\title{
Fertilization ecology of egg coats: physical versus chemical contributions to fertilization success of free-spawned eggs
}

\author{
Robert D. Podolsky \\ University of North Carolina, Department of Biology, CB 3280, Chapel Hill, NC 27599, USA \\ E-mail: podolsky@unc.edu
}

Accepted 19 March 2002

\begin{abstract}
Summary
Free-spawned eggs are typically enclosed within accessory structures that are shed early in development. Most research on the role of these structures in fertilization has focused on chemical constituents and their influence on sperm-egg interaction. Here I test an alternative hypothesis that accessory structures play an important physical role in fertilization by increasing the size and buoyancy of the egg, making it a better target for sperm. In the sand dollar Dendraster excentricus, the jelly coat increases egg target size sixfold. At nonsaturating sperm concentrations, fertilization declined consistently following jelly coat removal by two independent methods.

Sperm swimming speed, a key parameter in the model, did not vary as a function of sperm concentration or exposure to egg-water. The organic cost of jelly is a fraction of that of the ovum, providing an efficient means of extending target size beyond the ovum size that is optimal for larval or juvenile development. These results support the hypothesis that physical attributes of jelly coats can account for a significant portion of their contribution to fertilization, and may help to explain why coats and other accessory structures are often substantially larger than expected from the nature of chemical interactions between egg and sperm.
\end{abstract} Regression analysis using a standard fertilization kinetics model found that $54-73 \%$ of this decline on average was predicted by changes in the rate of sperm-egg collision, resulting from changes in egg target size and density.

Key words: jelly coat, target size, egg size, sperm swimming, fertilization success, energy investment, broadcast-spawning, sand dollar, Dendraster excentricus.

\section{Introduction}

Organisms that free-spawn eggs face the great potential reproductive risk of incomplete fertilization (Mortensen, 1938). Given evidence of at least occasional sperm limitation in marine environments (Levitan and Petersen, 1995; Yund, 2000), recent work has examined whether this risk is reduced by particular features of adults or gametes that could improve chances of sperm-egg encounter (Denny et al., 1992; Levitan et al., 1992; Petersen et al., 1992; Buckland-Nicks, 1993; Levitan, 1993; Babcock et al., 1994; Eckelbarger, 1994; Thomas, 1994a; Thomas et al., 1999). One common and conspicuous feature of free-spawned eggs is an extracellular 'accessory' structure that surrounds the ovum and is shed early in development (Strathmann, 1987). Although several functions have been proposed for these structures (Szollosi, 1964; Lambert and Lambert, 1978; Chia and Atwood, 1982; Buckland-Nicks, 1993; Thomas et al., 1999), most research on their role in fertilization has focused on chemical constituents and their effects on sperm-egg interaction. Compounds contained in or released by accessory structures have been shown to influence sperm physiology, respiration, motility, longevity, chemotaxis, species specificity and acrosome activation (SeGall and Lennarz, 1981; Suzuki, 1989; De Santis and Pinto, 1991; Patricolo and Villa, 1992; Villa and Patricolo, 1993; Bolton and Havenhand, 1996).

In addition to mediating chemical interactions, however, accessory structures can also alter the egg as a physical target for sperm. Jelly coats, follicle cells and egg hulls can double or triple the effective diameter of a free-spawned egg (Strathmann, 1987), substantially increasing cross-sectional ('target') area while also altering egg buoyancy. The potential importance of egg size for fertilization success was highlighted by Levitan (1993), who reasoned that under sperm limitation, larger eggs would be fertilized with greater probability because they present a larger target for sperm. As an alternative to the conventional view of accessory structures as primarily chemical in their action, here I test the hypothesis that accessory structures around free-spawned eggs can enhance fertilization success through a change in physical target size. This hypothesis has received speculation in previous studies (Rothschild and Swann, 1951; Vogel et al., 1982; Epel, 1991; Podolsky and Strathmann, 1996), and elsewhere I showed that overall target size is a good absolute predictor of the probability of fertilization (Podolsky, 2001). Previous studies have not, however, evaluated the importance of physical 


\section{R. D. Podolsky}

relative to other (e.g. chemical) effects of accessory structures on fertilization success.

Given several possible roles in fertilization, accessory structures could evolve in response to more than one factor. Using a combination of approaches, however, one can estimate the current importance to fertilization of a physical change in target size relative to other effects. I first use removal experiments to measure the effect of jelly coat presence on fertilization. Because this treatment potentially confounds the effects of physical target size with other effects, I then use a model of fertilization kinetics to predict the effect on fertilization of a size change equal to jelly coat removal. With the experimental data and the model predictions, I address the following questions. (1) What is the effect of jelly coat removal on fertilization rate? (2) How much of this effect can be accounted for by a simple change in target size? (3) Which parameters that could influence collision (e.g. sperm swimming speed) are influenced by the presence of jelly? (4) How does the effect of jelly on egg buoyancy influence fertilization? (5) What is the relative energetic cost of jelly as a means of enlarging target size? (6) What accounts for the remarkably large size of some accessory structures?

\section{Materials and methods \\ Handling of adults and gametes}

Adults of the sand dollar Dendraster excentricus Escholtz (Echinodermata: Echinoidea) were collected from intertidal habitats on Orcas Island, WA, USA and induced to spawn by standard methods (Strathmann, 1987). Sperm were collected undiluted ('dry') from the aboral surface. Hemocytometer counts of controlled dilutions showed a consistent concentration of dry sperm (mean $=2.55 \times 10^{6}$ sperm $\mu \mathrm{l}^{-1}$, $\mathrm{CV}=2.1 \%, N=10$ ), so that concentrations could be reliably reproduced by diluting known volumes from microcapillary tubes. Eggs were spawned directly into $0.45 \mu \mathrm{m}$ filtered sea water and kept cool before use.

The echinoid jelly coat is a glycoprotein-polysaccharide complex (Suzuki, 1989). In D. excentricus, the jelly coat is a firm, transparent, smoothly spherical shell with embedded pigment cells (Burke and Bouland, 1989; Podolsky, 2001). For size measurements, eggs were viewed in a suspension of Sumi ink, which is visibly excluded by the clear jelly coat (Schroeder, 1980). The coat is compressed inside the gonad but expands to full size within moments of contact with sea water (Podolsky, 2001). Fertilization is clearly evidenced by inflation of the vitelline envelope below the jelly coat and by cleavage. Embryos hatch within 1 day at ambient sea water temperatures, but jelly can disperse earlier (Strathmann, 1987).

Following convention and to avoid confusion, I use the term 'ovum' to refer strictly to the reproductive cell not including the jelly coat, and 'egg' to refer to an ovum with or without a jelly coat.

\section{Removal of jelly coats}

To maintain distinct treatments, these experiments require a species with jelly coats that persist on eggs unless actively removed. Attempts to remove jelly coats just after spawning by sieving, centrifugation and shaking were not completely successful and resulted in some egg damage. I therefore used a standard brief exposure to mildly acidified sea water to hydrolyze the coat (e.g. Harvey, 1956; Schroeder, 1986). For each fertilization trial, I removed jelly coats from half a cohort of freshly spawned eggs. The sea water was adjusted to approximately $\mathrm{pH} 5-5.5$ by adding drops of a weak $\mathrm{HCl}$ solution to the well-stirred egg suspension. Presence of the jelly coat on a sample of eggs was checked each minute using Sumi ink. After jelly coats had dispersed, I thoroughly washed both batches twice in filtered sea water, and standardized egg concentrations. Normal $\mathrm{pH}$ was restored by washing because jelly-free ova became unpredictably sticky when readjusting $\mathrm{pH}$ chemically. Ten trials were conducted using this removal method.

To test whether experimental results were an artifact of the acidification method, for five additional trials I used a second method of jelly coat removal. Each half-cohort was poured gently through Nitex mesh $(153 \mu \mathrm{m}$ diameter $)$ after brief washing in a $\mathrm{Ca}^{2+}$-free, neutral $\mathrm{pH}$ isotonic buffer $\left(500 \mathrm{mmol} \mathrm{l}^{-1} \mathrm{NaCl}, 27 \mathrm{mmol}^{-1} \mathrm{KCl}, 2 \mathrm{mmol}^{-1}\right.$ EDTA, $\mathrm{pH} 7.8$ at $23^{\circ} \mathrm{C}$ ) that weakens the coat and facilitates its mechanical removal (Salmon, 1982; Suprenant, 1986). Eggs were otherwise washed and handled as above.

\section{Fertilization assays}

Standard assays (Vogel et al., 1982; Mita et al., 1984; Levitan et al., 1991; Styan, 1998) were used to measure fertilization kinetics (proportion fertilized as a function of sperm concentration) for eggs with and without jelly coats. Assays were done in $20 \mathrm{ml}$ glass tubes held at $13^{\circ} \mathrm{C}$. Each trial included 32 experimental tubes ( 8 sperm concentrations $\times 2$ treatments $\times 2$ replicates). Final sperm concentrations ranged from $10^{-2}$ to $10^{4} \mu \mathrm{l}^{-1}$ in powers of 10 . Eggs from the two treatments ('intact' and 'coat-free') were added to the top of tubes immediately after sperm, to produce final egg concentrations of $0.05 \mu \mathrm{l}^{-1}$ in a total volume of $10 \mathrm{ml}$. Fertilization was blocked after $15 \mathrm{~min}$ by addition of an equal volume of $0.5 \mathrm{moll}^{-1} \mathrm{KCl}$ (Schuel, 1984). $15 \mathrm{~min}$ was more than adequate, based on time-course studies (Hagström, 1956b; Hagström and Markman, 1957), for sperm that had contacted the jelly coat to penetrate to the egg surface. I counted under a compound microscope the proportion of eggs fertilized in a sample of 150-200 eggs from each vial; replicates were averaged.

\section{Fertilization kinetics model}

I used a standard fertilization kinetics model (Vogel et al., 1982) to predict the effect of a change in target size on fertilization that would result from changes in sperm-egg collision. I did not include modifications to the model by Styan (1998) because (1) at sperm concentrations used in these experiments, there is little evidence of polyspermy for intact eggs; the vast majority undergo normal cleavage and 
development (consistent with observations by Schuel and Schuel, 1981; Nuccitelli and Grey, 1984; Dale, 1985), and (2) since jelly removal could influence properties of the egg that control polyspermy (Hagström, 1956a; Schuel and Schuel, 1981), evaluation of the importance of target size per se required a performance measure that was equivalent between treatments (e.g. lifting of the fertilization envelope, diagnostic of fertilization) rather than one that could confound fertilization frequency and polyspermy rate (e.g. normal development).

The Vogel et al. (1982) model is based on two assumptions, that sperm swimming direction is random and that sperm attach permanently to the first egg encountered. Vogel et al. (1982) and Levitan et al. (1991) tested the model for echinoid species and found good correspondence between predictions and data given variation in several parameters. The model was subsequently used to predict effects on fertilization of variation in gamete characters (Levitan, 1993, 1998; Podolsky and Strathmann, 1996; Styan, 1998). Here I use the model to predict the relative change in fertilization success given a size change equivalent to removing (or adding) a jelly coat.

The model predicts the proportion of eggs fertilized $\left(\varphi_{\infty}\right)$ given a set of initial conditions:

$$
\varphi_{\infty}=1-\exp \left\{-\frac{\beta}{\beta_{0}} \frac{S_{0}}{E_{0}}\left[1-\exp \left(-\beta_{0} E_{0} \tau\right)\right]\right\},
$$

where $S_{0}$ is initial sperm concentration $\left(\mu \mathrm{l}^{-1}\right), E_{0}$ is initial egg concentration $\left(\mu \mathrm{l}^{-1}\right) ; \tau$ is sperm 'longevity' (here, contact time, which was shorter than sperm half life; $s$ ); $\beta_{0}$ is 'rate constant of collision' $\left(\mathrm{mm}^{3} \mathrm{~s}^{-1}\right)$, estimated as the average sperm swimming speed $\left(u_{\mathrm{s}}, \mathrm{mm} \mathrm{s}^{-1}\right) \times$ the cross-sectional area of the egg target $\left(\pi r^{2}, \mathrm{~mm}^{2}\right)$; and $\beta$ is 'rate constant of fertilization' $\left(\mathrm{mm}^{3} \mathrm{~s}^{-1}\right)$. The model is fitted to data by estimating the parameter $\beta$ through iteration (SYSTAT, 1992). The dimensionless ratio $\beta / \beta_{0}$, termed the 'egg fertilizability' (Vogel et al., 1982; Levitan, 1993), is the probability of fertilization per collision, and is thus independent of egg target size.

For each trial and treatment, I used the fitted $\beta$ to estimate $\beta / \beta_{0}$ and computed the log-transformed sperm concentration at which $50 \%$ fertilization would be achieved $\left(\log F C_{50}\right)$. Within each trial I then determined $\log F C_{50}$ using the ratio $\beta / \beta_{0}$ characteristic of intact eggs, but adjusting target size to that of coat-free eggs. This calculation represents the expected effect of reducing target size while holding constant all size-independent parameters, including $\beta / \beta_{0}$. I used $\log F_{C_{50}}$ to estimate the proportion of the difference in fertilization between intact and coat-free eggs that is predicted by the change in target size alone. Given the exponential structure of the model, log-transformed values are on an appropriate scale for comparison. To demonstrate this, an equivalent analysis can be carried out using $\beta / \beta_{0}$ for coat-free eggs and adjusting the target size to match that of intact eggs. These reciprocal procedures produce identical results, as they should, only when $F C_{50}$ values are compared on the logarithmic scale.

\section{Parameter estimates}

The model includes three measured parameters (egg size with and without the jelly coat, sperm swimming speed and sperm half-life), and three that were controlled during experiments (sperm concentration, egg concentration and sperm-egg contact time).

\section{(1) Egg size}

Using an ocular micrometer on a compound microscope, I measured 10 ova and fully expanded jelly coats for each of six females. I used the grand mean for this parameter in the model (average $\mathrm{CV}$ for egg size was approximately $3.5 \%$ both within and among females; Podolsky, 1995).

\section{(2) Sperm speed}

Sperm diluted in filtered sea water $\left(10^{4} \mu 1^{-1}\right)$ were placed in a covered chamber of approximately $1.2 \mathrm{~mm}$ depth on a temperature-controlled $\left(13{ }^{\circ} \mathrm{C}\right)$ stage. Sperm were videotaped at an optical plane half way through the chamber $(0.6 \mathrm{~mm}$, or approximately 67 sperm body lengths, from the chamber walls) to minimize wall effects (Winet, 1973; Gee and Zimmer-Faust, 1997). Recordings were done in the time interval 8-10 min after dilution. A time-date generator recorded time to the nearest $0.01 \mathrm{~s}$ (at 30 frames s$^{-1}$ ), and sperm paths were later digitized. I measured 20 sperm per treatment, scoring only those that had covered, in a typical helical path, at least half of the field $(>300 \mu \mathrm{m})$ while in focus.

In addition to measuring sperm speed at a standardized concentration in filtered sea water, I tested for effects of two factors that varied in experiments and could have influenced sperm speed. (a) For echinoid sperm, respiration is inversely related to concentration (the 'respiratory dilution effect' or RDE; Chia and Bickell, 1983), which could alter swimming speed. To test for this effect, I measured speeds at four concentrations $\left(10^{3.5}, 10^{4}, 10^{4.5}\right.$ and $10^{5}$ sperm $\left.\mu \mathrm{l}^{-1}\right)$. Although these concentrations are at the high end of the range used in fertilization assays, the RDE should be apparent in this range (Chia and Bickell, 1983) and lower concentrations did not provide enough sperm for analysis. (b) Although the sperm of $D$. excentricus and most echinoids do not show chemotaxis (Miller, 1985), exposure to sea water that previously held eggs ('egg-water') is known in other species to increase sperm activity and longevity (Suzuki, 1989; Bolton and Havenhand, 1996). For two males at two temperatures $\left(10\right.$ and $\left.20.5^{\circ} \mathrm{C}\right) \mathrm{I}$ compared swimming speeds in filtered sea water and in 'eggwater', which was prepared by occasionally stirring a suspension of fresh eggs held at $4{ }^{\circ} \mathrm{C}$ in filtered sea water for $3 \mathrm{~h}$ before the eggs were removed.

\section{(3) Sperm longevity/contact time}

Sperm 'half-life' is the time after dilution when fertilization drops to $50 \%$ of its initial value. To estimate half-life, for seven males I measured fertilization at 5-8 time points after sperm dilution at the upper six concentrations used in fertilization assays. Diluted sperm were held at ambient water temperatures $\left(11-13^{\circ} \mathrm{C}\right)$. Time points used depended on sperm 
1660 R. D. Podolsky

concentration, ranging from 0 to $6 \mathrm{~h}$ for the most dilute and from 0 to $24 \mathrm{~h}$ for the most concentrated. Sperm were diluted in egg-water, because preliminary measurements suggested that exposure could reduce longevity (Bolton and Havenhand, 1996) and thereby provide a conservative estimate of half-life. In all trials, sperm were allowed contact with eggs for $15 \mathrm{~min}$ before $\mathrm{KCl}$ addition. For each sperm concentration and replicate, I performed a linear regression of $\log (\%$ eggs fertilized +1 ) on time after dilution, and used the regression equation to calculate a half-life for each concentration (Levitan, 1993).

\section{Effect of the jelly coat on egg sinking}

The fertilization kinetics model of Vogel et al. (1982) treats eggs as if they were stationary, using sperm speed alone to estimate rates of sperm-egg collision. In reality, eggs of most species are not neutrally buoyant, and their motion could contribute to the collision coefficient $\beta_{0}$. In addition, an egg sinking more rapidly through a sperm cloud would encounter more sperm per unit time, but would be in the presence of sperm for a shorter time (i.e. contact time, $\tau$ ).

In species that lack chemotaxis, a sinking egg can be considered to move through an isotropic field of nondirectional swimming sperm, as previously modeled for planktonic predators and prey, respectively (Gerritsen, 1980). In the original model, the rate coefficient of encounter $\left(E_{\mathrm{c}}\right.$, here relabelled $\beta_{0} *$ ) depended on three variables: the swimming velocities of predator and prey $\left(u_{\mathrm{f}}\right.$ and $u_{\mathrm{s}}$, denoting the faster and slower) and the radius of detection $\left(R_{\mathrm{d}}\right)$ :

$$
\beta_{0} *=\pi R_{\mathrm{d}^{2}}^{2}\left(\frac{u_{\mathrm{sl}^{2}}+3 u \mathrm{f}^{2}}{3 u_{\mathrm{f}}}\right) .
$$

These three variables $\left(R_{\mathrm{d}}, u_{\mathrm{f}}, u_{\mathrm{sl}}\right)$ are analogous to the effective egg radius $\left(R_{\mathrm{e}}\right)$, the sperm swimming speed $\left(u_{\mathrm{S}}\right)$, and the egg sinking speed $\left(u_{\mathrm{e}}\right)$. $\beta_{0}{ }^{*}$ has the same units as $\beta_{0}$ and can be substituted directly into Equation 1.

For eggs sinking through a finite cloud of sperm, sperm-egg contact time $\left(\tau^{*}\right)$ will be related directly to cloud diameter $\left(d_{\mathrm{c}}\right)$ and inversely to egg sinking speed $\left(u_{\mathrm{e}}\right)$, or $\tau^{*}=d_{\mathrm{c}} / u_{\mathrm{e}}$. In laboratory assays sperm are initially distributed uniformly, eggs are released at the top of the cloud, and $d_{\mathrm{c}}$ is fixed by container depth. Typically, eggs are allowed to settle and 'contact time' is assumed to be the length of time before fertilization is artificially stopped. In practice, for part of this time eggs will be concentrated at the container bottom, where fertilization rate is predicted to be strongly depressed by a high effective egg concentration (Vogel et al., 1982). Based on this prediction, I assume that fertilization at the bottom of the container is negligible relative to during the sinking period. The original model (no effect of egg sinking) and the model with this assumption (maximum effect) represent the two extremes of the potential contribution of egg sinking to collision rate under these conditions. The parameters used are summarized in Table 1.

To estimate the sinking speed of eggs with and without jelly
Table 1. Parameters used to fit the fertilization kinetics model to data from fertilization assays

\begin{tabular}{lcc}
\hline Parameter & Intact eggs & Coat-free eggs \\
\hline Target diameter $(\mathrm{mm})$ & 0.312 & 0.129 \\
Sperm speed, $u_{\mathrm{s}}\left(\mathrm{mm} \mathrm{s}^{-1}\right)$ & 0.195 & 0.195 \\
Sperm-egg contact time, $\tau$ & $900[478.9]$ & $900[223.2]$ \\
$\quad[\tau *](\mathrm{s})$ & & \\
Egg concentration $\left(\mu 1^{-1}\right)$ & 0.05 & 0.05 \\
Rate constant of collision, & $0.0149[0.0163]$ & $0.00249[0.00366]$ \\
$\quad \beta_{0}\left[\beta_{0}{ }^{*}\right]\left(\mathrm{mm}^{3} \mathrm{~s}^{-1}\right)$ & &
\end{tabular}

Values in square brackets were used in the second model incorporating changes in egg density and sinking speed.

coats, I assumed that eggs were spherical and used Stokes' equation (Vogel, 1981):

$$
u_{\mathrm{e}}=\left(\frac{2 g R_{\mathrm{e}}^{2}\left(\rho_{\mathrm{e}}-\rho_{\mathrm{sw}}\right)}{9 \mu_{\mathrm{sw}}}\right),
$$

where $\boldsymbol{g}$ is gravitational acceleration $\left(9800 \mathrm{~mm} \mathrm{~s}^{-2}\right), R_{\mathrm{e}}$ is effective egg radius $(\mathrm{mm}), \rho_{\mathrm{e}}$ is egg density $\left(\mathrm{mg} \mu \mathrm{l}^{-1}\right)$, and $\rho_{\mathrm{sw}}$ and $\mu_{\mathrm{sw}}$ are the density and viscosity $\left(\mathrm{mg} \mathrm{mm}^{-1} \mathrm{~s}^{-1}\right)$ of sea water at $13^{\circ} \mathrm{C}$ (Dorsey, 1968). Adding a jelly coat simultaneously affects egg radius and egg density. To measure the density of eggs with and without coats, I created fluids of variable specific gravity by mixing dilutions in sea water of the colloid Percoll (Pharmacia Inc.) (Pennington and Emlet, 1986). Densities of undiluted Percoll $\left(1.127 \mathrm{~g} \mathrm{ml}^{-1}\right)$ and sea water $\left(1.0225 \mathrm{~g} \mathrm{ml}^{-1}\right)$ were measured by weighing known volumes. Eggs were pipetted into a series of vials that contained an upper layer of sea water and a lower layer of a single concentration of Percoll, with specific gravities ranging from 1.024 to 1.028 (for intact eggs) and 1.050 to 1.058 (coat-free eggs) in 0.0005 increments. Eggs were considered to be denser than the lower layer if they continued to sink through it (Pennington and Emlet, 1986). I then used egg size and Stokes' law to calculate the sinking speed in still sea water of eggs with and without jelly coats.

\section{Organic cost of ovum and jelly}

To estimate organic investment I measured ash-free dry mass (AFDM) of eggs with and without jelly coats (Crisp, 1984; Omori and Ikeda, 1984; Jaeckle, 1995). AFDM of jelly was calculated by subtraction. Using AFDM to estimate total organic cost assumes that material costs reflect costs of synthesis, and ignores the differing energetic values of lipids, carbohydrates and proteins. These simplifications produce a conservative estimate of the ratio of ovum to jelly AFDM, because costs of synthesis and energetic values are greater for the major constituents of ova (protein and lipid; Turner and Lawrence, 1979) than of jelly (carbohydrate and protein; Paine, 1971; Crisp, 1984; Suzuki, 1989).

For each of eight females, I divided a cohort of fresh eggs and desalted both halves in isotonic (3.5\%) ammonium 
Fig. 1. Proportion of eggs fertilized as a function of sperm concentration for intact (filled circles) and coat-free eggs (open circles) in 15 individual trials. Graphs 1-10 show results for the acidification method of jelly coat removal; graphs 11-15 are for the neutral $\mathrm{pH} /$ mechanical method.

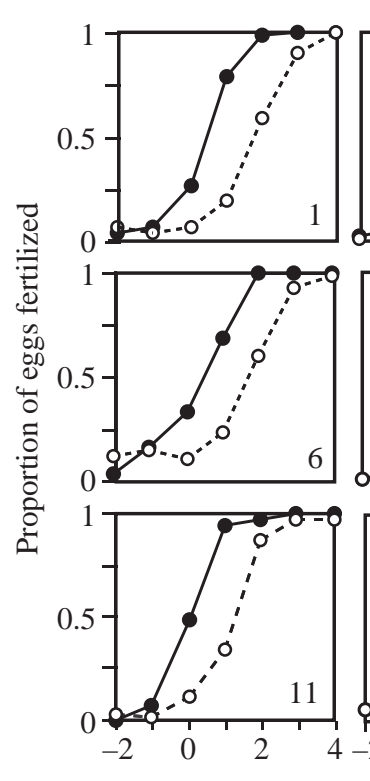

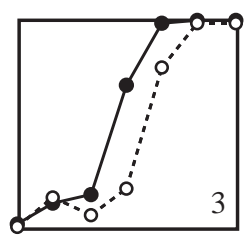
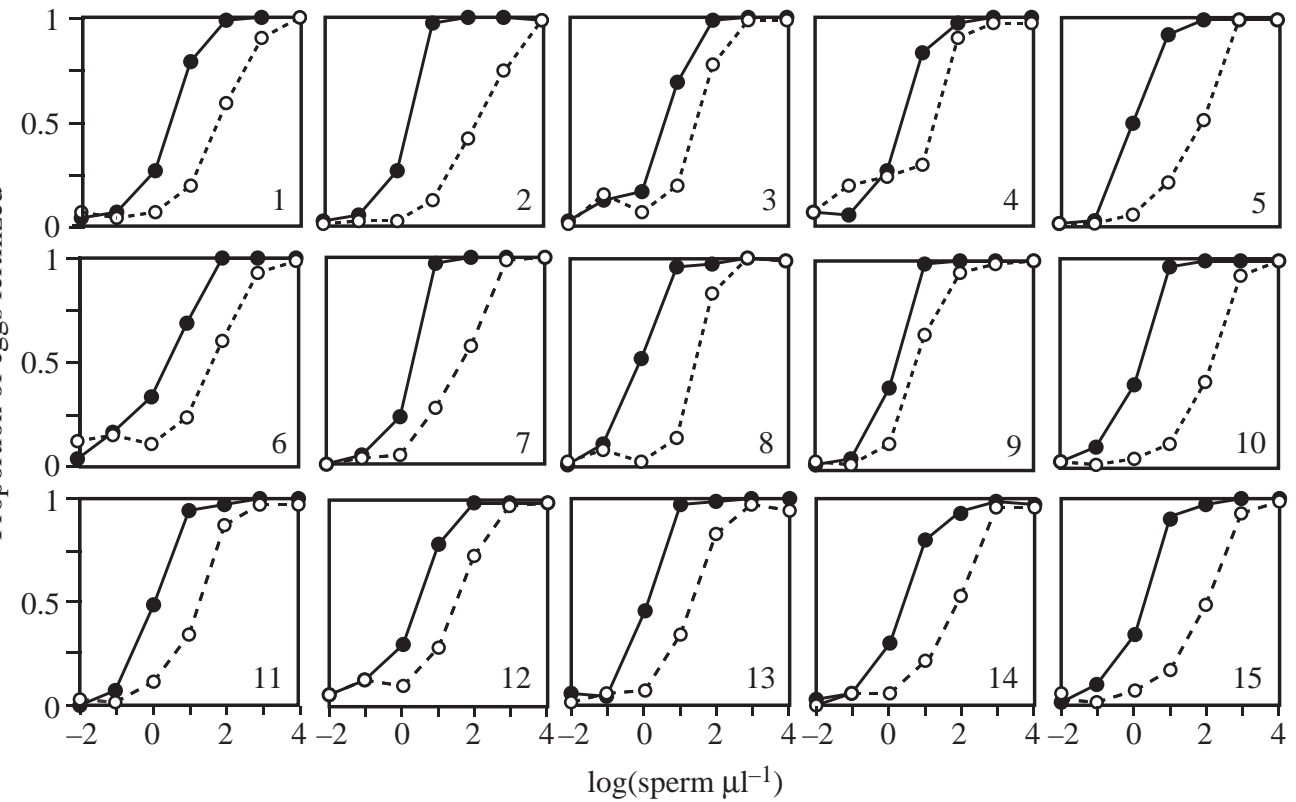

formate $\left(\mathrm{NH}_{4} \mathrm{COOH}\right)$. After exposure, jelly coats could be removed from one sample by pouring the eggs through a mesh screen $(153 \mu \mathrm{m})$. Eggs were allowed to settle and then resuspended in fresh buffer. I counted ten well-mixed subsamples to estimate the remaining number of eggs. I then collected eggs on a pre-ashed and pre-weighed GF-C filter under low vacuum (Omori and Ikeda, 1984). The filtered sample was dried to constant mass at $60^{\circ} \mathrm{C}$ for $24 \mathrm{~h}$, weighed, ashed at $500{ }^{\circ} \mathrm{C}$ for $12 \mathrm{~h}$, and reweighed. The difference in filter masses before and after ashing was divided by egg number to calculate AFDM per egg. Control filters that had been treated with ammonium formate were handled and measured in the same way.

\section{Results}

\section{Fertilization of eggs with and without jelly coats}

In each trial, fertilization decreased after jelly coat removal, particularly at intermediate sperm concentrations (Fig. 1). At high sperm concentrations, however, both treatments reached $100 \%$ fertilization, indicating that all eggs used in experiments were fertilizable. Average fertilization rate as a function of sperm concentration followed the sigmoid curves (Fig. 2) expected from the fertilization kinetics model (Vogel et al., 1982). Results from the two methods of jelly coat removal did not differ significantly, as demonstrated by the broad overlap of $95 \%$ confidence intervals (Fig. 2) and lack of significant differences between fitted values (see Table 2). Results from all 15 trials were therefore pooled for subsequent analyses.

\section{Model parameters}

Among six females, egg diameters (mean \pm S.E.M.) with and without the jelly coat were $311.9 \pm 4.3 \mu \mathrm{m}$ and $128.8 \pm 1.7 \mu \mathrm{m}$, respectively. Considering that eggs are nearly spherical, average volumes of the jelly coat and ovum were approximately $1.48 \times 10^{-1}$ and $1.12 \times 10^{-2} \mu \mathrm{l}$, respectively, a ratio of 13.2

Among seven males, average sperm swimming speed at $13^{\circ} \mathrm{C}$ was $195.0 \pm 9.8 \mu \mathrm{m} \mathrm{s}^{-1}$. Swimming speed did not vary as a function of sperm concentration over the 1.5 orders of magnitude tested $\left(F_{3,159}=0.28, P=0.84\right.$; see also Rothschild and Swann, 1950), nor as a function of whether sperm had been diluted in egg-water or filtered sea water $\left(F_{1,8}=0.438, P=0.53\right.$; Podolsky, 1995). Swimming speed varied significantly among males $\left(F_{4,159}=3.42, P=0.01\right.$; see also Gee and Zimmer-Faust, 1997).

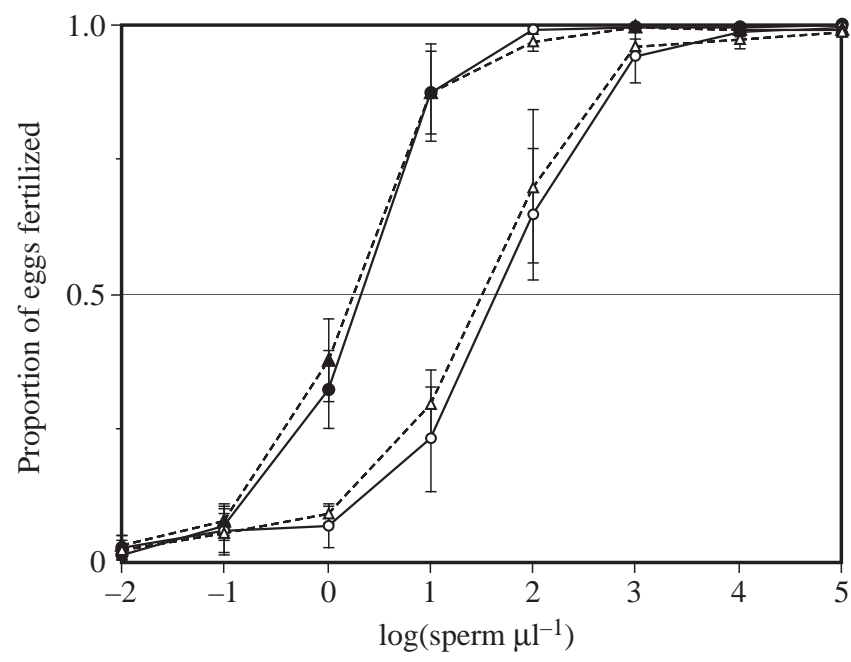

Fig. 2. Average fertilization rate as a function of sperm concentration for intact eggs (filled symbols) and coat-free eggs (open symbols). Data are separated by the two methods, acidification (circles, $N=10$ ) and mechanical removal (triangles, $N=5$ ). Error bars show $95 \%$ confidence intervals around the means for each sperm concentration and method. 
Table 2. Estimates of the parameter $\beta\left(\mathrm{mm}^{3} \mathrm{~s}^{-1}\right)$, the ratio $\beta / \beta_{0}$, and $\log \mathrm{FC}_{50}\left(\mu l^{-1}\right)$ for intact and coat-free eggs based on fertilization trials

\begin{tabular}{|c|c|c|c|c|c|c|c|c|}
\hline \multirow[b]{3}{*}{ Method/trial } & \multirow{3}{*}{$\begin{array}{c}\text { Experiment } \\
\text { number }\end{array}$} & \multirow[b]{3}{*}{$N$} & \multicolumn{6}{|c|}{ Egg } \\
\hline & & & \multicolumn{3}{|c|}{ Intact } & \multicolumn{3}{|c|}{ Coat-free } \\
\hline & & & $\beta\left(\times 10^{-4}\right)$ & $\beta / \beta_{0}\left(\times 10^{-2}\right)$ & $\log F C_{50}$ & $\beta\left(\times 10^{-4}\right)$ & $\beta / \beta_{0}\left(\times 10^{-2}\right)$ & $\log F C_{50}$ \\
\hline \multirow[t]{8}{*}{ Acidification } & 1 & & 2.75 & 1.85 & 0.59 & 0.11 & 0.43 & 1.88 \\
\hline & 2 & & 4.73 & 3.17 & 0.35 & 0.05 & 0.24 & 2.14 \\
\hline & 3 & & 1.86 & 1.25 & 0.75 & 0.18 & 0.73 & 1.65 \\
\hline & 6 & & 2.03 & 1.36 & 0.72 & 0.11 & 0.44 & 1.87 \\
\hline & 7 & & 4.39 & 2.95 & 0.38 & 0.11 & 0.44 & 1.87 \\
\hline & 8 & & 11.01 & 7.39 & -0.02 & 0.20 & 0.81 & 1.61 \\
\hline & 9 & & 7.22 & 4.85 & 0.17 & 1.22 & 4.87 & 0.83 \\
\hline & 10 & & 7.50 & 5.03 & 0.15 & 0.06 & 0.24 & 2.13 \\
\hline Mean \pm S.E.M. & & 10 & $5.42 \pm 1.02$ & $3.64 \pm 0.69$ & $0.37 \pm 0.09$ & $0.25 \pm 0.11$ & $1.01 \pm 0.45$ & $1.73 \pm 0.13$ \\
\hline & 14 & & 2.50 & 1.68 & 0.63 & 0.12 & 0.48 & 1.84 \\
\hline & 15 & & 6.27 & 4.21 & 0.23 & 0.07 & 0.30 & 2.04 \\
\hline Mean \pm S.E.M. & & 5 & $6.22 \pm 1.56$ & $4.18 \pm 1.05$ & $0.30 \pm 0.12$ & $0.24 \pm 0.07$ & $0.95 \pm 0.28$ & $1.63 \pm 0.15$ \\
\hline \multicolumn{9}{|l|}{ All trials } \\
\hline Mean \pm S.E.M. & & 15 & $5.69 \pm 0.83$ & $3.82 \pm 0.41$ & $0.34 \pm 0.05$ & $0.25 \pm 0.76$ & $0.99 \pm 0.35$ & $1.69 \pm 0.10$ \\
\hline
\end{tabular}

$\beta$, rate constant of fertilization; $\beta_{0}$, rate constant of collision; $\log F C_{50}, \log$-transformed sperm concentration at which $50 \%$ fertilization is achieved.

Values of $\beta$ were derived from a non-linear regression fit of the fertilization kinetics model to the data for each trial.

The ratio $\beta / \beta_{0}$ was calculated using values for $\beta_{0}$ of 0.0149 and $0.0025 \mathrm{~mm}^{3} \mathrm{~s}^{-1}$ for intact and coat-free eggs, respectively.

The concentration $F C_{50}$ was estimated by iteration using $\beta$ and other model parameters (Table 1).

Mean values of $\beta$ for coat-free eggs did not differ significantly between the two removal methods $(t=0.11, P<0.09)$.

As expected, sperm half-life increased as a function of sperm concentration, but was high at all concentrations (Fig. 3). Because average half-life even at the lowest sperm concentration was more than 10 times longer than the imposed

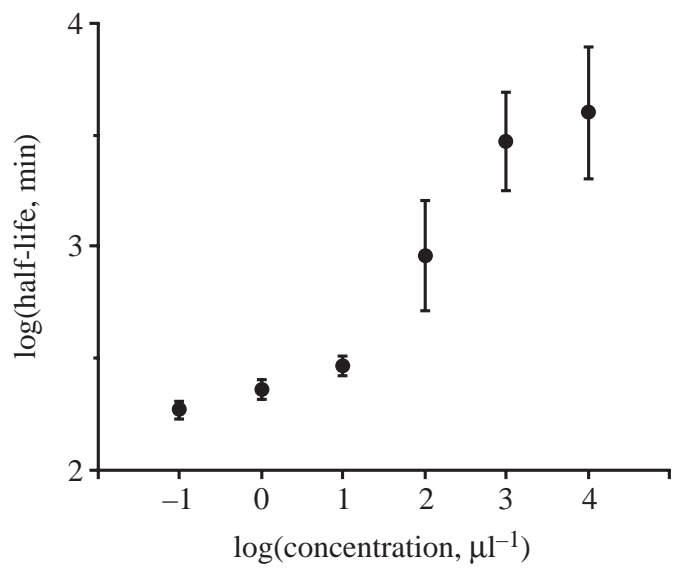

Fig. 3. Sperm half-life as a function of sperm concentration. Each point is the mean \pm S.E.M. for seven males of the regression estimate of half-life from a single dilution of sperm. Half-life was measured in egg-water and is therefore probably a conservative estimate. contact time of $15 \mathrm{~min}$, the parameter $\tau$ was set to $15 \mathrm{~min}$ (Vogel et al., 1982).

\section{Model fit and prediction of the effects of size change}

For each trial and treatment, I fitted the kinetics model (Equation 1) to fertilization data using the parameter values summarized in Table 1. The model accounted for 92-99\% of the variation in fertilization percentage. The fitted parameter $\beta$ (Table 2) was then used for each trial and treatment to plot fertilization kinetics as a function of sperm concentration. Using these curves, I calculated the log-transformed sperm concentration that would result in $50 \%$ fertilization (Table 2 , $\left.\log F C_{50}\right)$.

I then used the model to predict the effect on fertilization of a change in target size equal to removal of the jelly coat. For each trial, I generated a prediction curve by holding constant all size-independent parameters (egg concentration, contact time, sperm speed and $\beta / \beta_{0}$ for intact eggs) and setting target size equal to the value for coat-free eggs. For each prediction curve I calculated an expected $\log F C_{50}$ (Table 3 ), and the proportion of the difference in observed $\log F C_{50}$ between intact and coat-free eggs that was predicted by the change in target size. On average, $54 \%$ of the difference between 
Table 3. Predicted effects on fertilization of changes in egg target size and density

\begin{tabular}{|c|c|c|c|c|c|c|}
\hline \multirow[b]{3}{*}{ Method/trial } & \multirow{3}{*}{$\begin{array}{c}\text { Experiment } \\
\text { number }\end{array}$} & \multirow[b]{3}{*}{$N$} & \multicolumn{4}{|c|}{ Egg } \\
\hline & & & \multicolumn{2}{|c|}{ Size } & \multicolumn{2}{|c|}{ Size and density } \\
\hline & & & $\log F C_{50}$ & Proportion change & $\log F C_{50}$ & Proportion change \\
\hline \multirow[t]{10}{*}{ Acidification } & 1 & & 1.25 & 0.51 & 1.49 & 0.70 \\
\hline & 2 & & 1.01 & 0.37 & 1.26 & 0.51 \\
\hline & 3 & & 1.42 & 0.74 & 1.66 & 1.01 \\
\hline & 4 & & 1.19 & 0.82 & 1.44 & 1.13 \\
\hline & 5 & & 0.70 & 0.34 & 0.95 & 0.47 \\
\hline & 6 & & 1.38 & 0.57 & 1.62 & 0.79 \\
\hline & 7 & & 1.04 & 0.44 & 1.29 & 0.61 \\
\hline & 8 & & 0.64 & 0.41 & 0.89 & 0.56 \\
\hline & 9 & & 0.83 & 1.00 & 1.07 & 1.38 \\
\hline & 10 & & 0.81 & 0.33 & 1.06 & 0.46 \\
\hline Mean \pm S.E.M. & & 10 & $1.03 \pm 0.09$ & $0.55 \pm 0.07$ & $1.27 \pm 0.09$ & $0.76 \pm 0.10$ \\
\hline \multirow[t]{5}{*}{ Neutral/mechanical } & 11 & & 0.68 & 0.53 & 0.93 & 0.68 \\
\hline & 12 & & 1.21 & 0.61 & 1.46 & 0.83 \\
\hline & 13 & & 0.72 & 0.51 & 0.97 & 0.62 \\
\hline & 14 & & 1.29 & 0.55 & 1.53 & 0.75 \\
\hline & 15 & & 0.89 & 0.36 & 1.14 & 0.50 \\
\hline Mean \pm S.E.M. & & 5 & $0.96 \pm 0.12$ & $0.51 \pm 0.04$ & $1.20 \pm 0.12$ & $0.68 \pm 0.06$ \\
\hline \multicolumn{7}{|l|}{ All trials } \\
\hline Mean \pm S.E.M. & & 15 & $1.00 \pm 0.07$ & $0.54 \pm 0.05$ & $1.25 \pm 0.07$ & $0.73 \pm 0.07$ \\
\hline
\end{tabular}

$\log F C_{50}$ is the sperm concentration predicted by the model to achieve $50 \%$ fertilization for eggs that have the size-independent properties of intact eggs but a size (or size and density) change equivalent to removal of the jelly coat.

'\% change' gives the proportion of the total change in $\log F C_{50}$ from intact to coat-free eggs (data in Table 2) that is accounted for by the predicted $\log F C_{50}$. Mean values of $\%$ change were not significantly different between the two removal methods for size $(t=0.52, P<0.61)$ or size and density $(t=0.73, P<0.48)$.

treatments could be accounted for by a simple change in target size alone $[95 \% \mathrm{CI}=(44.4,63.7)$; Table 3$]$.

\section{Organic content and specific gravity of ovum and jelly}

Measurements of AFDM for eight females gave values of $0.260 \pm 0.025$ and $0.217 \pm 0.021 \mu \mathrm{g}$ (mean \pm S.E.M.) for eggs with and without jelly coats, respectively. The ovum thus constituted $83.6 \pm 9.1 \%$ of the AFDM per egg; given differences in volume, the ovum has 67.3 times the organic density of jelly. As a result, the addition of an average jelly coat enlarges volume approximately 14-fold and target area almost sixfold, but increases organic cost per egg only 1.19 -fold.

As described earlier, the latter value is a maximum estimate, because the major components of the ovum (protein and lipid) have higher energy content than those of jelly (protein and carbohydrate). To derive a minimum estimate, I assumed that jelly was all carbohydrate (lowest in energetic density) and used available data on the composition of ova. For nine species of echinoderms with eggs of a size similar to those of $D$. excentricus, the average percentage compositions of protein, lipid and carbohydrate were approximately $63 \%, 31 \%$ and $6 \%$ (Turner and Lawrence, 1979), which had average energetic contents of $23.7,39.6$ and $17.2 \mathrm{~kJ} \mathrm{~g}^{-1}$, respectively (Crisp, 1984). According to these figures, the jelly coat may increase organic investment per propagule by as little as 1.12 -fold. Jelly therefore comprises from 10 to $16 \%$ of the organic material cost of an egg.

Intact eggs and coat-free eggs sank through Percoll-sea water mixtures below specific gravities of 1.025 and 1.054, respectively. By subtraction, taking into account relative volumes, the specific gravity of jelly is around 1.023 , close to that of sea water $\left(1.0225\right.$ at $\left.13{ }^{\circ} \mathrm{C}\right)$.

\section{Incorporation of egg sinking into the model}

To incorporate egg sinking, I considered the speed at which eggs moved through the sperm cloud as well as the total time they remained suspended in the cloud (Vogel et al., 1982). The addition of a jelly coat increases egg size, but reduces egg density; these changes have opposing effects on sinking speed (Equation 3). The calculated net effect of adding a coat is a decrease in relative sinking speed, from 223 to $104 \mu \mathrm{m} \mathrm{s}^{-1}$. In theory this decrease would continue up to more than twice the observed size of jelly coats, at which point the effect of size would overcome the effect of density and sinking would begin again to increase (Podolsky, 1995).

The collision coefficient $\beta_{0} *$ increases only slightly when egg sinking is incorporated into the model (Fig. 4A). However, the total volume of water 'cleared' of sperm by the passing egg (the product $\beta_{0} * \tau^{*}$ ) increases steadily with an increase in jelly coat size (Fig. 4B). Depending on the water conditions, an 

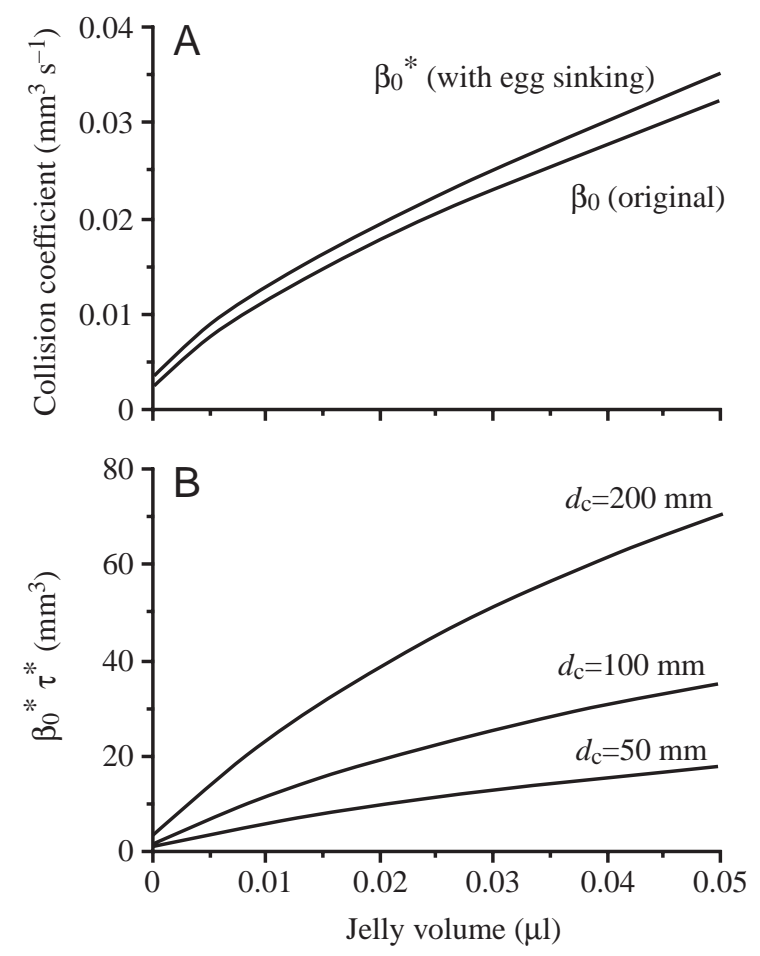

Fig. 4. Changes in model parameters as a function of jelly coat volume. (A) Effects on the collision coefficients $\beta_{0}$ (from the original model) and $\beta_{0} *$ (from the model incorporating egg sinking, Equation 2). (B) Effects on the product $\beta_{0} * \tau^{*}$, or the effective volume of water cleared of sperm while sinking, for different sperm cloud diameters $d_{\mathrm{c}}$.

intact egg may therefore have an additional benefit to sperm-egg collision of remaining suspended longer in a sperm cloud. To examine the potential contribution of egg sinking to assay results, I reanalyzed the fertilization data to produce new predicted $\log F C_{50}$ values, taking into account treatment differences in $\beta_{0}^{*}$ and $\tau^{*}$ (Table 3 ). With egg sinking included, $73.3 \%$ of the difference between intact and coat-free treatments was predicted by changes in size and density combined [95\% $\mathrm{CI}=(60.0,86.6)$; Table 3].

\section{Discussion \\ Chemical versus physical roles of the jelly coat in sperm-egg interaction}

A long history of research on the echinoid jelly coat has promoted the view that jelly primarily mediates chemical interactions between egg and sperm (Lillie, 1919; Tyler, 1941; Vasseur, 1952; Vacquier et al., 1979; Schuel, 1984; Garbers, 1989; Suzuki, 1989). Results for D. excentricus show that jelly can play an equally important physical role in sperm-egg encounter. At intermediate sperm concentrations, removal of the jelly coat consistently reduced fertilization; according to the fertilization kinetics model, $54-73 \%$ of this reduction is predicted by changes in egg size and density. This result is consistent with Levitan's (1993) hypothesis that target size significantly alters the probability of fertilization for individual eggs, and provides a quantitative answer to previous speculations (Rothschild and Swann, 1951; Vogel et al., 1982; Epel, 1991) about the contribution of accessory structures to fertilization through changes in target size.

Which aspects of jelly coat chemistry are likely to account for effects of jelly removal that were not related to size or density? The potential roles of chemical interaction before and during sperm-egg contact are well-established (SeGall and Lennarz, 1981; Suzuki, 1989; Vacquier and Moy, 1997), but the importance of any particular role can vary among species. In some, specific jelly components induce the sperm acrosome reaction (Vacquier and Moy, 1997) and may therefore be lost in the process of jelly removal, while in others, the role of jelly is less directly causal (Aketa and Ohta, 1977). Similarly, although sperm-activating peptides (SAPs) associated with jelly can stimulate sperm activity under certain conditions, their specific action and overall benefits to fertilization remain uncertain. According to one leading hypothesis, SAPs may stimulate sperm primarily to counteract the negative effects on sperm of jelly coat acidity, which is presumably maintained for a different function (Suzuki, 1989). In experiments presented here, dilution in egg-water had no significant effect on sperm swimming, indicating that SAP-enhanced swimming speed was probably not a factor in fertilization differences between intact and coat-free eggs.

Given the evident physical and chemical benefits of a jelly coat for sperm-egg encounter, it is worth noting some apparently conflicting reports in the literature. Some studies have similarly reported a 'cost' to jelly removal (Lillie, 1915; Tyler, 1941; Rothschild and Swann, 1951; McLaughlin and Humphries, 1978), some report little effect (Loeb, 1915; Farley and Levitan, 2001), and at least one investigator promoted a consistent 'benefit' (Hagström, 1956b, 1959; Hagström and Markman, 1957). In a brief review of this history, Vacquier et al. (1979) concluded that variable results were due to differences in methods (e.g. for jelly coat removal) and species biology (e.g. portion of jelly removed, role of jelly coat chemistry). However, it is equally important to recognize that variable conclusions have been based on measurements of different phenomena under different conditions. Specifically, studies that reported benefits (e.g. Hagström, 1956b; Vacquier et al., 1979) were concerned with the short-term (i.e. seconds) kinetics of sperm attachment or fertilization at spermsaturation. Under these conditions, the time course of sperm-egg collision may be short relative to penetration and attachment, and removing a jelly barrier could increase such rates. In contrast, studies that found costs to jelly removal measured the total proportion fertilized under sperm-limited conditions - conditions where the time course of collision regulates fertilization success (Vogel et al., 1982), and a smaller target size therefore reduces the proportion fertilized. Awareness of this distinction is critical to interpreting results. For example, if sperm are killed within a time period shorter than needed to penetrate the jelly coat - as typically done in 'rate' measurements (for estimates of the time course of jelly penetration, see Rothschild and Swann, 1951; Hagström, 
1956b, 1959; Hagström and Markman, 1957; Dale, 1985) then studies could confound time-dependent 'rates' with ultimate 'proportions' and conclude that jelly is insignificant or even detrimental to fertilization success (Hagström, 1956b; Farley and Levitan, 2001).

\section{Size and cost of accessory structures}

What accounts for the strikingly large size of many accessory structures (Strathmann, 1987)? Given substantial differences in organic density between ovum and jelly, an extracellular coat provides an efficient means of extending target size far beyond the ovum size that may be optimal for larval development (Podolsky, 2001). Upper limits on coat size could be set by diminishing returns of extra-embryonic investment (Lee and Strathmann, 1998) or by costs associated with increased polyspermy at large target size (Styan, 1998; but see below). Beyond its efficiency, jelly may also be more effective for target enhancement, because an ovum the size of an intact egg would also sink 12 times faster. Calculations showed that eggs sinking faster through a sperm cloud contact more sperm per unit time but a smaller total number of sperm. Given the benefits of prolonged suspension, it is probably not a coincidence that large accessory structures can bring eggs close to neutral buoyancy. Buckland-Nicks (1993) suggested a similar 'parachuting' function for the hulls of chiton eggs.

While this study documents one consequence of the presence of a jelly coat, optimal coat size could be influenced by other functional requirements. Although chemical effects on sperm could select for large coat size, the relationship between jelly volume and chemical sperm activation is unknown, and residual jelly remaining after coat removal can be sufficient for the acrosome reaction (Vacquier et al., 1979). On the other hand, accessory structures have been implicated in several processes where size could be important, including the prevention of both polyspermy (Lambert and Lambert, 1981; Patricolo and Villa, 1992) and hybridization (De Santis and Pinto, 1991; Vilela-Silva et al., 2002). Coat thickness, for example, could help to regulate the arrival of sperm at the egg surface, through chemically mediated agglutination or physical delays in penetration (Schuel, 1984). Jelly coats might thereby benefit fertilization at both low and high sperm concentrations, by increasing sperm collision and regulating sperm passage, respectively (R. D. Podolsky, in preparation). Finally, jelly coats have also been cited for a role in egg or embryo protection (Szollosi, 1964; Chia and Atwood, 1982), including the stabilization of eggs under extreme shear forces as spawn is released through the echinoderm gonoduct (Thomas and Bolton, 1999; Thomas et al., 1999). However, because this latter benefit accrues before the coat has expanded (Podolsky, 2001) it is unlikely to explain large variation in coat size.

Among the structural materials that could enlarge target size (e.g. jelly coats, hulls, follicle cells), jelly may have an additional advantage: because most size expansion occurs after release (Podolsky, 2001), jelly is especially suitable for packing inside the female test. In $D$. excentricus, a jelly coat compressed to just $50 \%$ of its full thickness triples the space available for egg storage relative to a rigid structure of the same final size. In similar fashion, adults of chiton species that brood young tend to be smaller than broadcast-spawning relatives, and their eggs tend to have more reduced and flattened hulls (Eernisse, 1988). This pattern is consistent with the hypothesis that limitations on storage space (Buckland-Nicks, 1993), and modes of reproduction where target size and buoyancy have a weaker effect on sperm egg-encounter, will favor the evolution of smaller egg accessory structures.

\section{Generalizations of this analysis}

The strength of conclusions about the magnitude of the physical role of accessory structures depends on at least three assumptions. First, I assume that the fertilization kinetics model (Equation 1) predicts the effect of a physical change in target size, as summarized in the collision parameter $\beta_{0}$. Information for $D$. excentricus and other echinoids (Vogel et al., 1982) supports both basic assumptions of the model (random swimming and permanent attachment): sperm of $D$. excentricus and most echinoids do not show chemotaxis (Miller, 1985), and the acrosome reaction following sperm-egg contact incapacitates sperm, regardless of whether they attach permanently (Vacquier, 1979). In species without chemotaxis, physical target size is a good absolute predictor of both sperm-egg collision (Farley and Levitan, 2001) and the probability of fertilization (Podolsky, 2001) under spermlimited conditions. Clearly, the definition of 'target size' would be complicated by chemotaxis, because attractants can change the effective distance at which a sperm 'contacts' the target (Jantzen et al., 2001). An additional contribution of chemotaxis would support the general conclusion that accessory features, whether physical or chemical, provide an economical alternative to investment in the ovum for increasing target size.

Second, I assume that jelly coat removal did not damage ova. Fertilization reached $100 \%$ under sperm saturation in all trials, indicating that all eggs could potentially be fertilized. The $\mathrm{pH}$ used for coat removal in trials was higher than those reported to cause damage ( $\mathrm{pH}=3.5-4.5$; Hagström, 1956b; Vacquier et al., 1979) and is in a range reported to avoid damage (Loeb, 1915) or actually to enhance fertilization rate (Hagström, 1959; Vacquier et al., 1979). Indistinguishable results using an independent removal method indicate that mild acidification was not the cause of reduced fertilization at intermediate sperm concentrations, a confirmation paralleled in earlier work (Hagström and Markman, 1957). Given the need for a resilient coat during experiments, in practice any removal method runs a risk of damaging some ova. Jelly coats have been removed without apparent ill effect by mechanical shear forces associated with several thousand revolutions in a beaker (Farley and Levitan, 2001); the alternative method used here was judged to be the gentlest available. In any case, if some damage to ova occurred with any method, then the proportion of the total effect that the model attributed to physical target size would be reduced. That is, my estimates of the importance 
of egg size and density relative to jelly coat chemistry would then be conservative.

Third, I assume that results from laboratory experiments are relevant to natural conditions. Application of these results depends on understanding particular patterns of flow in the field and how they affect gamete movement (Young et al., 1992; Levitan, 1995). Dendraster excentricus inhabits a wide range of habitats, from intertidal to shallow subtidal and from calm to high current or surge-influenced (Merril and Hobson, 1970; Telford, 1983; Emlet, 1986). Particular depth, current, and wave conditions will determine the distribution of eggs after spawning and, therefore, the importance of factors like egg sinking. As demonstrated here, differences in egg suspension time even over short vertical distances can have a big influence on the probability of sperm-egg collision. Even for organisms that occur and potentially spawn in higher energy habitats (Denny and Shibata, 1989; Mead and Denny, 1995), target size is likely to play a role in sperm-egg collision regardless of whether gametes move through self-propulsion, gravity or water motion. The primary goal of this analysis has been to estimate the relative importance of physical versus chemical contributions of the jelly coat. Given that water motion could interfere more with chemical cues used by sperm to encounter eggs, the relative importance of physical attributes could be greater under turbulent conditions.

\section{Responses to environmental variation at the gamete stage}

Renewed interest in the fertilization ecology of marine invertebrates has focused mainly on the importance of adult traits: body size, aggregation, synchrony, habitat location and population size and density (Pennington, 1985; Yund, 1990; Levitan, 1991; Denny et al., 1992; Levitan et al., 1992; Oliver and Babcock, 1992; Babcock et al., 1994; Levitan and Young, 1995; Atkinson and Yund, 1996). This study adds to growing evidence for gamete traits as responses to variation in fertilization conditions. In addition to exploring the ecological role of sperm chemotaxis (Jantzen et al., 2001), recent work has highlighted several physical traits, including: sperm size, morphology and energy storage in low-energy deep sea environments (Eckelbarger, 1994); egg size (Levitan, 1993) and shape (Podolsky, 1995) and their effects on sperm egg encounter; egg accessory structures and their role in protecting eggs from shear during and after spawning (Mead and Denny, 1995; Thomas et al., 1999) and in guiding sperm to the egg surface (Buckland-Nicks, 1993); positive egg buoyancy and the compression of gamete interactions into two dimensions at the air-water interface (Oliver and Willis, 1987); and spawn viscosity and its adjustment in response to flow conditions (Thomas, 1994a,b; Meidel and Yund, 2001). These examples, involving properties of sperm, eggs and aggregate spawned material, illustrate the important relationship between gamete structural traits and physical processes in understanding the fertilization ecology of broadcast-spawners.

I am indebted to Oscar Iribarne for his contribution to this research. C. Biermann, J. Kingsolver, C. E. Lee, D. Pfennig,
R. Strathmann, A. Welch and two reviewers provided helpful comments or assistance. This work was supported by a University of North Carolina URC grant and NSF grant IBN9912084.

\section{References}

Aketa, K. and Ohta, T. (1977). When do sperm of the sea-urchin Pseudocentrotus depressus undergo the acrosome reaction at fertilization? Dev. Biol. 61, 366-372.

Atkinson, O. S. and Yund, P. O. (1996). The effect of variation in population density on male fertilization success in a colonial ascidian. J. Exp. Marine Biol. Ecol. 195, 111-123.

Babcock, R. C., Mundy, C. N. and Whitehead, D. (1994). Sperm diffusion models and in situ confirmation of long-distance fertilization in the freespawning asteroid Acanthaster planci. Biol. Bull. 186, 17-28.

Bolton, T. F. and Havenhand, J. N. (1996). Chemical mediation of sperm activity and longevity in the solitary ascidians Ciona intestinalis and Ascidiella aspersa. Biol. Bull. 190, 329-335.

Buckland-Nicks, J. (1993). Hull cupules of chiton eggs: parachute structures and sperm focusing devices? Biol. Bull. 184, 269-276.

Burke, R. D. and Bouland, C. (1989). Pigmented follicle cells and the maturation of oocytes in the sand dollar, Dendraster excentricus. Dev. Growth Differ. 31, 431-437.

Chia, F.-S. and Atwood, D. G. (1982). Pigment cells in the jelly coat of sand dollar eggs. In Echinoderms: Proceedings of the International Conference (ed. J. M. Lawrence), pp. 481-484. Rotterdam: Balkema.

Chia, F.-S. and Bickell, L. R. (1983). Echinodermata. In Reproductive Biology of Invertebrates (ed. K. G. Adiyodi and R. G. Adiyodi), pp. 545-620. Chichester: John Wiley \& Sons.

Crisp, D. J. (1984). Energy Flow Measurements. In Methods for the Study of Marine Benthos (ed. N. A. Holme and A. D. McIntyre), pp. 284-372. Oxford: Blackwell Scientific Publications.

Dale, B. (1985). Sperm receptivity in sea-urchin oocytes and eggs. J. Exp. Biol. 118, 85-98.

De Santis, R. and Pinto, M. R. (1991). Gamete self-discrimination in ascidians: a role for the follicle cells. Mol. Reprod. Dev. 29, 47-50.

Denny, M. W., Dairiki, J. and Distefano, S. (1992). Biological consequences of topography on wave-swept rocky shores. I. Enhancement of external fertilization. Biol. Bull. 183, 220-232.

Denny, M. W. and Shibata, M. F. (1989). Consequences of surf-zone turbulence for settlement and external fertilization. Amer. Nat. 117, 838-840.

Dorsey, N. E. (1968). Properties of Ordinary Water-Substance. New York: Hafner Publications.

Eckelbarger, K. J. (1994). Ultrastructural features of gonads and gametes in deep-sea invertebrates. In Reproduction, Larval Biology, and Recruitment of the Deep-Sea Benthos (ed. C. M. Young and K. J. Eckelbarger), pp. 137-157. New York: Columbia University Press.

Eernisse, D. J. (1988). Reproductive patterns in six species of Lepidochitona (Mollusca: Polyplacophora) from the Pacific Coast of North America. Biol. Bull. 174, 287-302.

Emlet, R. B. (1986). Larval production, dispersal, and growth in a fjord: a case study on larvae of the sand dollar Dendraster excentricus. Mar. Ecol. Prog. Ser. 31, 245-254.

Epel, D. (1991). How successful is the fertilization process of the sea urchin egg? In Biology of Echinodermata (ed. T. Yanagisawa, I. Yasumasu, C. Oguro, N. Suzuki and T. Motokawa), pp. 51-54. Rotterdam: Balkema.

Farley, G. S. and Levitan, D. R. (2001). The Role of Jelly Coats in Sperm-egg Encounters, Fertilization Success, and Selection on Egg Size in Broadcast Spawners. Amer. Nat. 157, 626-636.

Garbers, D. L. (1989). Molecular basis of fertilization. Ann. Rev. Biochem. 58, 719-742.

Gee, C. C. and Zimmer-Faust, R. K. (1997). The effects of walls, paternity and ageing on sperm motility. J. Exp. Biol. 200, 3185-3192.

Gerritsen, J. (1980). Adaptive responses to encounter problems. In The Evolution and Ecology of Zooplankton Communities (ed. W. C. Kerfoot), pp. 52-62. Hanover, NH: University Press of New England.

Hagström, B. E. (1956a). The effect of removal of the jelly coat on fertilization in sea urchins. Exp. Cell Res. 10, 740-743.

Hagström, B. E. (1956b). Studies on the fertilization of jelly-free sea urchin eggs. Exp. Cell Res. 10, 24-28. 
Hagström, B. E. (1959). Further experiments on jelly-free sea urchin eggs. Exp. Cell Res. 17, 256-261.

Hagström, B. E. and Markman, B. (1957). Further studies on the fertilization of jelly-free sea urchin eggs. Acta Zool. 38, 219-222.

Harvey, E. B. (1956). The American Arbacia and Other Sea Urchins. Princeton, NJ: Princeton University Press.

Jaeckle, W. B. (1995). Variation in the size, energy content, and biochemical composition of invertebrate eggs: correlates to the mode of larval development. In Ecology of Marine Invertebrate Larvae (ed. L. R. McEdward), pp. 49-77. Boca Raton: CRC Press.

Jantzen, T. M., de Nys, R. and Havenhand, J. N. (2001). Fertilization success and the effects of sperm chemoattractants on effective egg size in marine invertebrates. Mar. Biol. 138, 1153-1161.

Lambert, C. C. and Lambert, G. (1978). Tunicate eggs utilize ammonium ions for flotation. Science 200, 64-65.

Lambert, C. C. and Lambert, G. (1981). Formation of the block to polyspermy in ascidian eggs. Time course, ion requirements, and the role of the accessory cells. J. Exp. Zool. 217, 291-295.

Lee, C. E. and Strathmann, R. R. (1998). Scaling of gelatinous clutches: effects of siblings' competition for oxygen on clutch size and parental investment per offspring. Amer. Nat. 151, 293-310.

Levitan, D. R. (1991). Influence of body size and population density on fertilization success and reproductive output in a free-spawning invertebrate. Biol. Bull. 181, 261-268.

Levitan, D. R. (1993). The importance of sperm limitation to the evolution of egg size in marine invertebrates. Amer. Nat. 141, 517-536.

Levitan, D. R. (1995). The ecology of fertilization in free-spawning invertebrates. In Ecology of Marine Invertebrate Larvae (ed. L. R. McEdward), pp. 123-156. Boca Raton, FL: CRC Press.

Levitan, D. R. (1998). Does Bateman's principle apply to broadcast-spawning organisms? Egg traits influence in situ fertilization rates among congeneric sea urchins. Evolution 52, 1043-1056.

Levitan, D. R. and Petersen, C. (1995). Sperm limitation in the sea. Trends Ecol. Evol. 10, 228-231.

Levitan, D. R., Sewell, M. A. and Chia, F.-S. (1991). Kinetics of fertilization in the sea urchin Strongylocentrotus franciscanus: interaction of gamete dilution, age, and contact time. Biol. Bull. 181, 371-378.

Levitan, D. R., Sewell, M. A. and Chia, F.-S. (1992). How distribution and abundance influence fertilization success in the sea urchin Strongylocentrotus franciscanus. Ecology 73, 248-254.

Levitan, D. R. and Young, C. M. (1995). Reproductive success in large populations: Empirical measures and theoretical predictions of fertilization in the sea biscuit Clypeaster rosaceus. J. Exp. Mar. Biol. Ecol. 190, 221-241.

Lillie, F. R. (1915). Sperm agglutination and fertilization. Biol. Bull. 28, $18-33$.

Lillie, F. R. (1919). Problems of Fertilization. Chicago: University of Chicago Press.

Loeb, J. (1915). On the nature of conditions which determine or prevent the entrance of the spermatozoan into the egg. Amer. Nat. 49, 257-285.

McLaughlin, E. W. and Humphries, A. A. J. (1978). The jelly envelopes and fertilization of eggs of the newt, Notophthalmus viridescens. J. Morphol. 158, 73-90.

Mead, K. S. and Denny, M. W. (1995). The effects of hydrodynamic shear stress on fertilization and early development of the purple sea urchin Strongylocentrotus purpuratus. Biol. Bull. 188, 46-56.

Meidel, S. K. and Yund, P. O. (2001). Egg longevity and time-integrated fertilization in a temperate sea urchin (Strongylocentrotus droebachiensis). Biol. Bull. 201, 84-94.

Merril, R. J. and Hobson, E. S. (1970). Field observations of Dendraster excentricus, a sand dollar of western North America. Amer. Midland Nat. 83, 595-624.

Miller, R. L. (1985). Demonstration of sperm chemotaxis in Echinodermata: Asteroidea, Holothuroidea, Ophiuroidea. J. Exp. Zool. 234, 383-414.

Mita, M., Hino, A. and Yasumasu, I. (1984). Effect of temperature on interaction between eggs and spermatozoa of sea urchin. Biol. Bull. 166, 68-77.

Mortensen, T. (1938). Contributions to the study of the developmental and larval forms of echinoderms IV. Kong. Danske Vidensk. Selsk. Skrift. Nat. Math. Afd. 9 Raekke 7, 1-59.

Nuccitelli, R. and Grey, R. D. (1984). Controversy over the fast, partial, temporary block to polyspermy in sea urchins: a reevaluation. Dev. Biol. 103, 1-17.
Oliver, J. and Babcock, R. (1992). Aspects of the fertilization ecology of broadcast spawning corals: sperm dilution effects and in situ measurements of fertilization. Biol. Bull. 183, 409-417.

Oliver, J. K. and Willis, B. L. (1987). Coral-spawn slicks in the Great Barrier Reef: preliminary observations. Mar. Biol. 94, 521-529.

Omori, M. and Ikeda, T. (1984). Methods in Marine Zooplankton Ecology. New York: John Wiley and Sons.

Paine, R. T. (1971). The measurement and application of the calorie to ecological problems. Ann. Rev. Ecol. Syst. 2, 145-164.

Patricolo, E. and Villa, L. (1992). Ascidian interspecific fertilization. II. A study of the external egg coating in hybrid crosses. Anim. Biol. 1, 9-15.

Pennington, J. T. (1985). The ecology of fertilization of echinoid eggs: the consequences of sperm dilution, adult aggregation, and synchronous spawning. Biol. Bull. 169, 417-430.

Pennington, J. T. and Emlet, R. B. (1986). Ontogenetic and diel vertical migration of a planktonic echinoid larva, Dendraster excentricus (Eschsholtz): occurrence, causes, and probable consequences. J. Exp. Mar. Biol. Ecol. 104, 69-95.

Petersen, C. W., Warner, R. R., Cohen, S., Hess, H. C. and Sewell, A. T. (1992). Variable pelagic fertilization success: implications for mate choice and spatial patterns of mating. Ecology 73, 391-401.

Podolsky, R. D. (1995). Effects of temperature, viscosity, and small size on early life-history processes in the sand dollar Dendraster excentricus. $\mathrm{PhD}$ Dissertation, University of Washington, Seattle, WA, USA.

Podolsky, R. D. (2001). Egg size and fertilization success: an analysis of selection on correlated characters. Evolution 55, 2470-2478.

Podolsky, R. D. and Strathmann, R. R. (1996). Evolution of egg size in freespawners: consequences of the fertilization-fecundity trade-off. Amer. Nat. 148, 160-173.

Rothschild, L. and Swann, M. M. (1950). The fertilization reaction in the sea-urchin: the effect of nicotine. J. Exp. Biol. 27, 400-406.

Rothschild, L. and Swann, M. M. (1951). The fertilization reaction in the sea-urchin: the probability of a successful sperm-egg collision. J. Exp. Biol. 28, 403-416.

Salmon, E. D. (1982). Mitotic spindles isolated from sea urchin eggs with EGTA lysis buffers. Meth. Cell Biol. 25, 69-105.

Schroeder, T. E. (1980). The jelly canal marker of polarity for sea urchin oocytes, eggs and embryos. Exp. Cell Res. 128, 490-494.

Schroeder, T. E. (ed.) (1986). Echinoderm Gametes and Embryos. Methods in Cell Biology, vol. 27. Orlando: Academic Press.

Schuel, H. (1984). The prevention of polyspermic fertilization in sea urchins. Biol. Bull. 167, 271-309.

Schuel, H. and Schuel, R. (1981). A rapid sodium-dependent block to polyspermy in sea urchin eggs. Dev. Biol. 87, 249-258.

SeGall, G. K. and Lennarz, W. J. (1981). Jelly coat induction of the acrosome reaction in echinoid sperm. Dev. Biol. 86, 87-93.

Strathmann, M. F. (1987). Reproduction and Development of Marine Invertebrates of the Northern Coast. Seattle: University of Washington Press.

Styan, C. (1998). Polyspermy, egg size, and the fertilization kinetics of freespawning marine invertebrates. Amer. Nat. 152, 290-297.

Suprenant, K. A. (1986). Tubulin-containing structures. In Methods in Cell Biology (ed T. E. Schroeder), pp. 189-216. Orlando: Acadamic Press.

Suzuki, N. (1989). Sperm-activating peptides from sea urchin egg jelly. Bioorg. Mar. Chem. 3, 47-70.

SYSTAT (1992). Statistics, Version 5.2. Evanston, IL: Systat, Inc.

Szollosi, D. (1964). Unique envelope of a jellyfish ovum: the armed egg. Science 163, 586-587.

Telford, M. (1983). An experimental analysis of lunule function in the sand dollar Mellita quinquiesperforata. Mar. Biol. 76, 125-134.

Thomas, F. I. M. (1994a). Physical properties of gametes in three sea urchin species. J. Exp. Biol. 194, 263-284.

Thomas, F. I. M. (1994b). Transport and mixing of gametes in three freespawning polychaete annelids, Phragmatopoma californica (Fewkes), Sabellaria cementarium (Moore), and Schizobranchia insignis (Bush). J. Exp. Mar. Biol. Ecol. 179, 11-28.

Thomas, F. I. M. and Bolton, T. F. (1999). Shear stress experienced by echinoderm eggs in the oviduct during spawning: potential role in the evolution of egg properties. J. Exp. Biol. 202, 3111-3119.

Thomas, F. I. M., Edwards, K. A., Bolton, T. F., Sewell, M. A. and Zande, J. M. (1999). Mechanical resistance to shear stress: The role of echinoderm egg extracellular layers. Biol. Bull. 197, 7-10. 


\section{R. D. Podolsky}

Turner, R. L. and Lawrence, J. M. (1979). Volume and composition of echinoderm eggs: implications for the use of egg size in life-history models. In Reproductive Ecology of Marine Invertebrates (ed. S. E. Stancyk), pp. 25-40. Columbia, SC: University of South Carolina Press.

Tyler, A. (1941). The rôle of fertilizin in the fertilization of eggs of the seaurchin and other animals. Biol. Bull. 81, 190-205.

Vacquier, V. D. (1979). The fertilizing capacity of sea urchin sperm rapidly decreases after induction of the acrosome reaction. Dev. Growth Differ. 212, 61-69.

Vacquier, V. D., Brandriff, B. and Glabe, C. G. (1979). The effect of soluble egg jelly on the fertilizability of acid-dejellied sea urchin eggs. Dev. Growth Differ. 21, 47-60.

Vacquier, V. D. and Moy, G. W. (1997). The fucose sulfate polymer of egg jelly binds to sperm REJ and is the inducer of the sea urchin sperm acrosome reaction. Dev. Biol. 192, 125-135.

Vasseur, E. (1952). The Chemistry and Physiology of the Jelly Coat of the Sea Urchin Egg. Stockholm: Wenner Gren Institute for Experimental Biology.

Vilela-Silva, A.-C. C. E. S., Castro, M. O., Valente, A.-P., Biermann, C.
H. and Mourão, P. A. S. (2002). Sulfated Fucans from the Egg Jellies of the Closely Related Sea Urchins Strongylocentrotus droebachiensis and Strongylocentrotus pallidus Ensure Species-specific Fertilization. J. Biol. Chem. 277, 379-387.

Villa, L. and Patricolo, E. (1993). Role of the follicle cells in ascidian sperm-egg interaction. Anim. Biol. 2, 175-184.

Vogel, H., Czihak, G., Chang, P. and Wolf, W. (1982). Fertilization kinetics of sea urchin eggs. Math. Biosci. 58, 189-216.

Vogel, S. (1981). Life in Moving Fluids. Princeton, NJ: Princeton University Press .

Winet, H. (1973). Wall drag on free-moving ciliated micro-organisms. J. Exp. Biol. 59, 753-766.

Young, C. M., Tyler, P. A., Cameron, J. L. and Rumrill, S. G. (1992). Seasonal breeding aggregations in low-density populations of a bathyal echinoid, Styocidaris lineata. Mar. Biol. 113, 603-612.

Yund, P. O. (1990). An in situ measurement of sperm dispersal in a colonial marine hydroid. J. Exp. Zool. 253, 102-106.

Yund, P. O. (2000). How severe is sperm limitation in natural populations of marine free-spawners? Trends Ecol. Evol. 15, 10-13. 